\title{
Nasal Cavity
}

National Cancer Institute

\section{Source}

National Cancer Institute. Nasal Cavity. NCI Thesaurus. Code C12424.

The proximal portion of the respiratory passages on either side of the nasal septum lying between the floor of the cranium and the roof of the mouth and extending from the face to the pharynx. The nasal cavity is lined with ciliated mucosa, extending from the nares to the pharynx. 